\title{
PROCUREMENT OF MATERIALS AND COMPONENTS FOR MANUFACTURING ACTIVITY
}

Contribution provides insight into various forms of procurement of material inputs in production companies in the Slovak Republic. Compares the traditional approach with modern systems and highlights the main features of each system with respect to logistics activities.

Keywords: Material procurement, inbound logistics, purchase, Just-in-Time, Just-in Sequence.

\section{Introduction}

With increasing demand for provision of goods and services from external sources, the procurement of these sources has an important role. Procurement may be defined as a purchase of materials and services from external organizations in order to support all operations in the plant - from production to marketing, sales and logistics. Instead of general term "procurement", sometimes also terms such as purchase, supply management, etc. are used. However, they always include the following activities: selection of suppliers, negotiation of price, delivery terms and conditions, payment conditions, etc. If the plant creates a long term relation with key suppliers - partners, the importance of procurement and its possible contribution in terms of profitability will increase.

Basically, there are two different approaches to manage the enterprise procurement. There are systems which work under so-called "push principle" and systems using a "pull principle".

In the system of "Make to stock" the movement of material and information is based on a long-term forecasting demand. Reverse thrust principle means that the movement of the material is carried out only if the following stage of the supply chain is required and, therefore, the system is often called "Make to Order" system.

Supply chains often use both principles, the push principle at the beginning and the pull principle at the last stages of the supply chain.

The main reasons are clear - a growing trend towards wider adaptation and the fact that the value of the product throughout its movement is reflected in the cost calculation. The place where the system changes to the push pull system is called the point of separation.
The article compares the three most widely used forms of procurement:

- Form described as a traditional approach to public procurement because it is based on the push principle - it is an older approach,

- Just in Time procurement,

- Just in Sequence procurement.

Although the last two systems work on the principle of thrust, the differences in their organization and operation are great.

\section{Description of procurement systems in use today}

Company logistics as a subsystem of the company can be divided into the following areas (sub-systems):

a) basic areas of logistics:

- purchase (acquisition) logistics,

- production logistics,

- distribution logistics,

b) cross-sectional areas of logistics:

- transport logistics,

- logistics information,

- storage logistics,

- it also includes flow of finances, which is in the opposite direction to the direction of material flow and is essential for the functioning of the entire logistics chain and for providing the company's existence [1].

The scope of activities of basic types of logistics is shown in Fig. 1.

\footnotetext{
* Marian Sulgan, Jarmila Sosedova

Department of Water Transport, Faculty of Operation and Economics of Transport and Communications, University of Zilina, Slovakia,

E-mail: marian.sulgan@fpedas.uniza.sk
} 


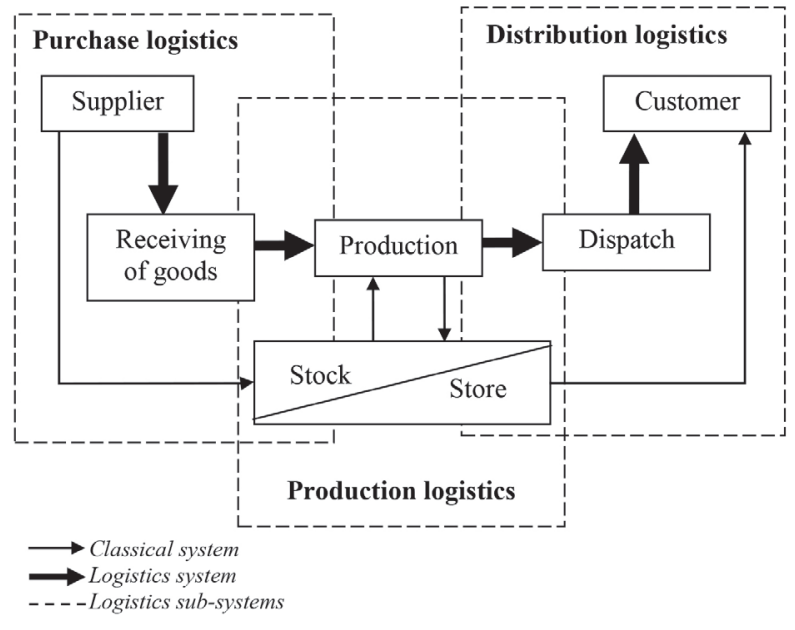

Fig. 1 Basic types of logistics

Purchase (acquisition) logistics means a complex of logistics tasks and measures in preparation and execution of purchase of all material items that are necessary for provision of respective production or other activity of the company. It deals with all activities connected with material flow of raw materials, auxiliary materials and production materials, purchased parts from the purchase market for the input store or directly for production.

Areas of purchase logistics cover the following logistics tasks: - Make or Buy - strategy (together with production and purchase),

- purchase adjusted to production (determination of outgoing types, time and place),

- minimization of transport costs,

- data concerning packaging, binding, quality control, etc.

The most important role of purchase logistics is procurement of all raw materials, components, intermediate products and other supplies for production activities.

Each of the forms of procurement is found in several alternatives. Therefore, choosing the best alternative is very important.

\section{Traditional procurement}

Traditional procurement works in a "Push" principle, which is based on a long term forecasting demand. In this system, it is necessary to store a large number of stocks. There are two basic inventory management systems under traditional procurement [2]:

- Fixed order quantity of inventory held in the system,

- Fixed limited inputs of inventories in the system.

Quantity of material in each supply is constant, the interval between deliveries varies depending on the actual material consumption. The order is executed when the stock reaches a predetermined minimum level, the so-called Order point. Stocks in the system must be constantly monitored. This causes higher requirements on technical and information support of inventory management. Order quantity can be determined by optimizing the total cost function. Optimized ordering is labeled „Economic order quantity".

The system also examines the time interval. The requirement is adjusted to achieve the required level of stock. This procedure is used for a large number of items from the same supplier.

\section{Just in Time procurement}

It is the most widespread logistics technology in the field of supply, production and distribution. It satisfies the requirements on delivery of particular material, parts and components in production or on distribution of finished products (goods) in the distribution segment by its supply JIT (Just in Time); it means accurately and in compliance with the deadlines according to a need of withdrawing segment. This system supplies small amounts and in the latest possible moment, so the supplies are very frequent. The customer is a dominating article of this chain, to which the supplier has to adapt in such a way that in supplies it creates such manipulation units that will smoothly pass through all points of handling operations in a subsequent flow. The aim of JIT strategy is to produce in line with demand through simplification and rationalization of material flows. Deliveries must be synchronized with the production.

A task of JIT is to eliminate any losses [2]. The final ideal state is production without keeping stocks. This concept also includes a method of quality detection as well as the planning of production and material flows, in particular:

- choice of means of transport,

- placement decision,

- relations with suppliers.

The method is considered a tool for decreasing stocks and providing early supply to the plant. The plants using this method concentrate particularly on elimination of time downtimes. The objective is to be closer to the customer and to react faster on changes in needs. The real benefits are based on shortening the entire production cycle. Saving time during the whole cycle results in acceleration of capital turnover, increases performance and flexibility and satisfies the consumer. The location of suppliers closer to the factory (the place of consumption) usually means a reduction in distribution costs. If the rapid reduction of stock is not simultaneously accompanied with the saving of time in a production process, it may cause serious threat to the plant. To adapt to the needs of customers, the suppliers currently use synchronized strategies within JIT system when there is only minimal safety stock for the case, e.g., of unexpected delay of transport or emancipation strategies when the plant produces 
several supplies to the store, from where they are dispatched according to customer needs in JIT mode.

The advantage of this system is propinquity of the supplier and the customer. On the contrary, this strategy may be limited in the case of not very long transfer distance, border controls and freight forwarding equipage, in the case of not complex composite assortment, in-adaptable structures of suppliers production or unsolved problem of connection in the material flow (not aligning means of transports, unsuitable way of unloading, ineffective quantitative and qualitative control upon receiving goods, long follow-up inter-operational handling) or in information flows (in not smooth transmission of information). The first four above mentioned factors may be eliminated by accepting the emancipation strategy in the form of inserted common warehouse operated by a contractual freight forwarding agency, which in this case also ensures the receiving of supplies sent by the supplier to the warehouse on the basis of appeal to the customer (e.g. storage operations and their evidence, supplies from the warehouse for consumption according to direct appeals in JIT mode). Moreover, this warehouse also provides information services and handles formalities connected with supply transport.

If several suppliers are involved in the subsystem of transit storage supplies, the freight forwarder also performs completion or compilation of items within supply from the warehouse, according to the order required by the customer. Importance of freight forwarders' involvement in storage systems increases in current trend of distribution channels influenced by global logistics. In general, it is possible to say that JIT system operates in 4 basic fields:

- improvement of stocks turnover,

- better customer service,

- reduction of storage area,

- improvement of response time.

The implementation of JIT system may also cause decrease of distribution costs, decrease of transportation costs, improvement of products quality from the suppliers and reduction of number of carrier haulers and suppliers [3]. Within JIT system, importance of transport as a segment of logistics increases and high requirements are put on it:

- shorter and more reliable time of transportation,

- more sophisticated communication,

- smaller number of carrier haulers with long-term relations,

- effective design of vehicles and equipment for material handling,

- high-quality decision-making models regarding the use of transport vehicles (own, public, contractual).

However, JIT has also some negatives. The emphasis on creating the best conditions for smooth production with minimal stocks may lead to deterioration of conditions for the customer and limitations of the sub-suppliers. On the other hand, the companies with several suppliers may become too dependent. Similarly, JIT system makes high demands on organization of transport process (correct timing of supply, reliability of means of transport, etc.). It is very difficult to implement JIT system, because it requires significant costs to ensure effective operation of the entire system. The most important benefits of the system can be seen only after certain time of its operation. The process of material system includes a sub-system of material availability, material appeal, storage, material preparation, visual management and information system.

Extended JIT system with sequential order is called JIS (Just in Sequence), which is described in the next section.

\section{Just in Sequence procurement}

As already indicated, JIS is a modification of a JIT system. However, this adjustment is very important, so the system is currently marked as a separate - JIS - which is used mainly in automotive industry. Most supply companies for automakers in Slovakia use the JIS system. Suppliers adapt their own production plans so that they can deliver their products at the right time, in the right quantity, at the right place and in a certain order - the sequence.

The need for such a system was caused by increasing variability of input material items (operating units and modules), as well as because of the need of adaptation to the final product according to customer requirements. Within the JIS, it is possible to adjust production to the required specifications according to the customer - that is to modify the specification of individual components and modules. Information is transformed into the production plan, which must be adapted to current ranking cars on the production line. Information for the supplier is generated automatically as a sequence of pulses, which are also automatically sent normally through electronic data interchange [4].

The sequence determines the order in which the modules must be delivered - they are usually shipped several hours before installation into the product. In view of the normal operation of supply, it is possible to perform the shifting process in two basic forms:

- the supplier delivers components under the JIT system in a location near the final assembly of the final product, the components are from this place gradually moved into the assembly line,

- the supplier supplies components directly to the working position on the assembly line.

In the first case, the providers are called third-party logistics providers. They provide services and perform sequential warehouse operations. Products are distributed in the right order and at the right time. Products are loaded on suitable pallets and transported to the assembly line.

In the second case, the supplier places the components into special containers or pallets in compliance with the desired 
sequence, and such containers are loaded into a vehicle with respect to the order of their unloading. According to the scheduled time the supplier delivers components and a vehicle stops at a particular location that is closest to the assembly line. From there, the containers are moved to the assembly point on the production line. The same car will be venturing empty containers back to the supplier.

\section{Comparison of procurement forms with respect to the logistics activities}

Table 1 shows the differences between various forms of acquisition with regard to the selected logistics criteria. We can see that the warehouse facility prefers decline in inventories (JIT, JIS). The result is a lower probability of generating unproductive inventory. It also appears that the amount by the optimum sequence will significantly reduce inventory. This is the way of maintaining inventory levels (the system maintains inventory levels continuously). Although the system with fixed time constraint is less demanding for the management, maintenance has the potential surplus stock and is vulnerable to supply shortages [5].

In the field of material handling there is an important criterion called "the number of touch points." These points are necessary to ensure the desired order of material inputs into production (it covers all handling activities and all equipment procurement).

Criteria such as accuracy and frequency of the provision of supplies and the distance between the supplier and the customer are very important in the logistics area, especially for demanddriven systems (JIT, JIS).

Accuracy is very necessary for the provision of services under JIT and JIS. Therefore, the entire process must be supported by an efficient information system. It is preferred to use systems based on a modular structure which allows individual processes (modules) to be effectively altered, replaced, moved, or to create entirely new processes. JIS system has relatively high demands on the quality of the information system.

In the purchase, we can see that the traditional form of procurement prefers a multi-sourcing model where the price is the key criterion for vendor selection. Conversely, JIT and JIS systems prefer to focus on one of the selected supplier. The supplier must provide high quality products because the organization of re-delivery is too expensive.

\section{Conclusion}

The paper deals with the characteristics and differences in the forms of contracts that are currently applied in Slovakia. Supply was evaluated in terms of managing logistics and purchasing activities. Differences were examined through a set of selection criteria within the main logistics activities. The main differences concern the storage and inventory management (inventory levels) and transport (frequency and accuracy). Also, logistics, information and communication require some changes (compatibility information systems, increased reaction time, etc.). The procurement differs mainly in the area of supplier selection, the ordering, the control activity and invoicing.

\section{Acknowledgements}

This paper presents results of work supported by the Slovak Scientific Grant Agency of the Slovak Republic under the project VEGA $1 / 0331 / 14$.

Some of the differences between forms of procurement

Table 1

\begin{tabular}{|l|l|l|l|}
\hline Purchasing activity & Traditional approach & Just-in-time & Just-in-sequence \\
\hline Choosing supplier & $\begin{array}{l}\text { Two or more suppliers, key } \\
\text { choosing criterion is price }\end{array}$ & $\begin{array}{l}\text { Often only one supplier who has } \\
\text { to be able to ensure frequent and } \\
\text { accurate deliveries }\end{array}$ & $\begin{array}{l}\text { Often only one supplier who has to be able to } \\
\text { assure deliveries in required sequence }\end{array}$ \\
\hline Changes in orders & $\begin{array}{l}\text { Delivery time and quality are often } \\
\text { changed at the last moment }\end{array}$ & $\begin{array}{l}\text { Delivery time and quality are fixed, } \\
\text { quantity can be adjusted within } \\
\text { predetermined range according to } \\
\text { the current need }\end{array}$ & $\begin{array}{l}\text { Delivery time and quality are fixed, in case of } \\
\text { changed according to the new sequence }\end{array}$ \\
\hline Supplier evaluating to be & $\begin{array}{l}\text { Quality evaluation, delivery } \\
\text { deviations up to 10\% are accepted }\end{array}$ & Deviations are not accepted, price is fixed and it is based on clear calculation \\
\hline Invoicing & Payment after each delivery & Invoices are gathered, payment usually once a month \\
\hline
\end{tabular}

Source: authors 


\section{COMMNICOIIONS}

\section{References}

[1] KUBASAKOVA, I: Just in Time Versus Just in Sequence. Transportation and Communications: the Internet magazine 2012. ISSN 1336-7676, pp. 250-256.

[2] KAlASOVA, A., KRCHOVA, Z.: Analysis of Road Traffic Accident Rate in the Slovak Republic and Possibilities of its Reduction Through Telematic Applications. Transport Systems Telematics. Conference, Katowice, 2010. ISBN 978-3-642-16471-2, pp. 463-468.

[3] DAVID, A.: Project Support Inland Waterway Transport and Logistics in the Danube Corridor. Conference New Trends in Water Transport, Zilina, 2012. ISBN 978-80-554-0553-7.

[4] STOPKA, O.: Trends in Security Storage Halls. $6^{\text {th }}$ Intern. Conference CMDTUR 2012, Zilina. EDIS - Publishing University of Zilina 2012, pp. 309-315, ISBN-978-80-554-0512-4.

[5] KAMPF, R., LIZBETIN, J., LIZBETINOVA, L.: Requirements of a Transport System User. Communications - Scientific Letters of the University of Zilina, No. 4, 2012, pp. 106-108. ISSN 1335-4205. 